\title{
Impact of co-located welfare advice in healthcare settings: prospective quasi-experimental controlled study
}

\author{
Charlotte Woodhead, Mizanur Khondoker, Robin Lomas and Rosalind Raine
}

\section{Background}

Evaluations of primary healthcare co-located welfare advice services have been methodologically limited.

Aims
To examine the impact and cost-consequences of co-located
benefits and debt advice on mental health and service use.

\section{Method}

Prospective, controlled quasi-experimental study in eight intervention and nine comparator sites across North Thames. Changes in the proportion meeting criteria for common mental disorder (CMD, 12-item General Health

Questionnaire); well-being scores (Shortened Warwick and Edinburgh Mental Well-being Scale), 3-month GP consultation rate and financial strain were measured alongside funding costs and financial gains.

\section{Results}

Relative to controls, CMD reduced among women (ratio of odds ratios (rOR) $=0.37,95 \% \mathrm{Cl} 0.20-0.70$ ) and Black advice recipients ( $\mathrm{rOR}=0.09,95 \% \mathrm{Cl} 0.03-0.28$ ). Individuals whose advice resulted in positive outcomes demonstrated improved well-being scores ( $\beta$ coefficient 1.29, 95\% Cl 0.25-2.32). Reductions in financial strain ( $\mathrm{rOR}=0.42,95 \% \mathrm{Cl} 0.23-0.77$ ) but no changes in 3-month consultation rate were found. Per capita, advice recipients received $£ 15$ per $€ 1$ of funder investment

\section{Conclusions}

Co-located welfare advice improves short-term mental health and well-being, reduces financial strain and generates considerable financial returns.

\section{Declaration of interest}

None.

\section{Copyright and usage}

(C) The Royal College of Psychiatrists 2017. This is an open access article distributed under the terms of the Creative Commons Attribution (CC BY) licence.
Associations between poor mental health and social disadvantage such as indebtedness and unstable housing are well documented. ${ }^{1}$ Individuals with mental ill health are also more likely to have difficulties accessing support and advice for social welfare issues. ${ }^{2-5}$ Subjective experiences of financial difficulties ('financial strain') predict onset and duration of common mental disorders. ${ }^{6}$ The impact on patients of economic hardships associated with recession and austerity exert additional strain on general practitioners (GPs), particularly those working in socially disadvantaged areas. ${ }^{7,8}$ One approach to reducing psychological distress linked to social disadvantage has been to co-locate welfare advice services (for example for issues related to debt and access to welfare benefits) in healthcare settings. ${ }^{9,10}$ Previous evaluations report an impact on increased income and debt management but there is limited evidence in terms of health or service use. ${ }^{11}$ Existing research is limited by small sample sizes, lack of robust comparator groups, attrition and lack of exploration of underlying pathways of effect, ${ }^{10}$ which may have an impact on continued funding of such services. ${ }^{9}$ We undertook a prospective controlled quasi-experimental study of the effects of co-located welfare benefits and debt advice on mental health and GP consultation frequency. We also compared funding costs of the service to the financial gains for advice recipients.

\section{Method}

\section{Setting and study design}

This quasi-experimental study (online supplement DS1) was part of a mixed-methods evaluation of co-located welfare advice services within North London conducted between December 2015 and December 2016; qualitative findings are reported elsewhere. ${ }^{11}$ Co-location involves local Citizens Advice service staff providing specialist in-depth advice at general practices, primarily about welfare benefits and debts. Patients can self-refer or be signposted by practice staff. We prospectively compared individuals accessing co-located advice at eight GP sites with a propensity score weighted comparison group. Individuals were recruited over 8 months and followed up for 3 months. The evaluation received National Health Service (NHS) ethical approval from the London-Harrow Research Ethics Committee (REC) (NHS REC reference: 15/LO/1260).

\section{Sample size}

Intervention group size was limited by the number of individuals that the services had the capacity to support per week and time constraints linked to deadlines for subsequent commissioning decisions. The target sample size $(n=816 ; n=204$ intervention and $n=612$ control) therefore included a larger comparison group to increase analytical power. Sample size was calculated to detect a moderate effect size $(d)$ of 0.4 with $90 \%$ power and was sufficient to detect smaller effect sizes $(d=0.35)$ with $80 \%$ power (online supplement DS1). ${ }^{10}$

\section{Recruitment}

Advice group

All individuals aged $18+$ years accessing co-located welfare advice services in eight sites during the recruitment period were eligible. Individuals waiting to see an adviser were approached by researchers. Those whose English was insufficient to understand the information sheet and consent form were excluded $(3.2 \%$ of 
those approached). In line with recommendations from prior reviews of research with 'hard to reach' groups, ${ }^{12,13}$ individuals

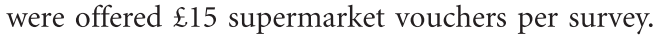

\section{Comparison group}

We identified individuals aged $18+$ years from which to generate a propensity score weighted comparison group. ${ }^{14}$ The propensity score estimates the probability that a given individual would receive co-located advice, summarising a range of variables associated with receiving advice into a single probability value. ${ }^{15}$ Weighting reduces confounding from selection bias by assigning more weight to controls whose propensity scores are closer to those of advice recipients. ${ }^{16}$

We contacted potentially eligible comparator participants in three ways (Fig. 1, online supplement DS1). In each, no identifiable data were disclosed to researchers before individuals provided informed consent. First, individuals of similar age group, ethnicity and gender to those accessing local co-located advice services in the past 12 months (assessed using Citizens Advice data) were identified from practice lists of nine local general practices. These practices did not host advice services but were in areas with similar levels of social disadvantage. ${ }^{17}$ Based on an anticipated response rate of $10 \%, 5419$ patients over all practices were identified and posted recruitment packs on behalf of their practice. Packs included information sheets, consent forms, baseline surveys and two return envelopes for consent forms and surveys (addressed to different locations). We expected that responders to these contact attempts may differ to advice recipients. Therefore, we worked with a local housing association to contact 490 tenants comparable with advice recipients in terms of age group, gender and ethnicity. Finally, as Black African and Caribbean individuals were underrepresented in GP-based returns, and to achieve the required sample size, we worked with community organisations to advertise the study.

\section{Data collection}

Surveys were self-report, taking approximately $15 \mathrm{~min}$ to complete. All materials were piloted (online supplement DS1). After survey refinement, baseline data were collected from advice recipients at general practices prior to their advice session and from controls by post. We collected follow-up data from both groups by post 3 months later. This follow-up period was chosen first, to increase confidence in a direct association between advice receipt and changes in mental health, particularly in a multiply disadvantaged population in which other factors could influence outcomes and override the benefits of advice. Second, to minimise attrition - a limitation of research with socioeconomically disadvantaged groups, optimising statistical power and reducing the risk of bias. ${ }^{12,13}$ Third, based on Citizens Advice data indicating a mean issue resolution time of 3 months.

To determine whether the study sample was representative of co-located advice recipients, anonymised demographic data for all individuals accessing services at participating sites during the recruitment period were extracted from the Citizens Advice information technology (IT) platform.

\section{Outcome measures}

Prior research demonstrates that the relationship between low income and CMDs is mediated by experiences such as perceived financial strain and indebtedness. ${ }^{3,6,18}$ Psychosocial theories linking such experiences with poor mental health suggest that they act as stressors, increasing the risk of poor health when demands exceed individual coping resources. ${ }^{18,19}$ Further, patients in more deprived areas have higher rates of GP consultations associated with psychological difficulties linked to problems such as financial hardship. Outcome measures were therefore selected to examine evidence for improved mental health and reduced consultations, and whether this was influenced by reduced financial strain.

\section{Mental health and well-being}

We used the 12-item General Health Questionnaire (GHQ-12) to measure the primary outcome, presence/absence of CMD. The GHQ-12 is a widely used and validated screening instrument for common symptoms of mental distress, encompassing comorbid symptoms of anxiety and depression. ${ }^{20,21}$ Each item has four response categories on a Likert scale ranging from 'not at all' to 'much more than usual'. The 'GHQ-method' of scoring ${ }^{20}$ was used; assigning a score of 1 to 'rather more' or 'much more than usual', and a score of 0 to 'not at all' or 'no more than usual' responses. Total scores range from 0 to 12 . Scores of four or more (GHQ 'caseness') indicate a level of symptoms likely to need further treatment. ${ }^{20}$ We counted missing items as low scores, ${ }^{22}$ those responding to fewer than four items were coded as missing.

Well-being was measured using the seven-item Shortened Warwick-Edinburgh Mental Well-being Scale (SWEMWBS). ${ }^{23}$ This ordinal scale evaluates positive mental health over the past fortnight, assessing respondents' agreement with statements such as, 'I've been feeling optimistic about the future'. Responses are measured on a five-point scale ranging from 'none of the time' to 'all of the time'. Summed scores are used as a continuous variable, greater scores indicate more positive well-being. Scores range from 7 to 35 and are transformed to a total score. ${ }^{24}$ Respondents answering three or more items were non-missing. The average score of non-missing items was imputed for remaining items. ${ }^{25}$

\section{Consultation frequency}

Self-reported consultation frequency was assessed by asking individuals to report numbers of GP appointments over the past 12 months (baseline), and over the past 3 months (baseline and follow-up).

\section{Financial strain}

Perceived financial strain was measured with an item used in UK household panel surveys ${ }^{26}$ asking, 'How would you say you were managing your finances these days?' Response options are on an ordinal scale from 'living comfortably' to 'finding it very difficult'.

\section{Financial support-seeking}

We examined coping and support-seeking for financial pressures at baseline and follow-up using items adapted from previous surveys $^{27,28}$ (online supplement DS2). Participants were asked what they would do (for example 'use credit card') and who they would go to (such as 'GP'), if their income did not cover their costs. Questions about how financial stressors affected them (for example 'physical health') were asked before enquiring who they would go to for support with these experiences. Any changes since receiving advice (welfare advice group only) and access to welfare advice services since baseline were assessed at follow-up.

\section{Propensity score covariates}

Independent variables to be included in the model were measured at baseline (Table 1). These included categorical variables: age group, gender, ethnicity, marital status, employment status, educational attainment, household composition, tenure, monthly 
household income, long-term health conditions and financial capability. Financial capability was assessed with four items indicating past-year problems meeting housing-related payments. ${ }^{29}$ We summed the number of problems and created a binary variable $(0 / 1+)$.

\section{Accessing the advice service}

To explore further the accessibility of co-located advice services, the baseline survey included questions about how they had heard about the service (for example 'word of mouth'); preferred location of welfare advice (GP/elsewhere); and, whether they had spoken to their GP about the issue they were seeing the adviser about (yes/no). Open-ended questions explored reasons for the latter two items, thematically coding responses for analyses (online Table DS1).

\section{Cost-consequences analysis}

As a return-on-investment measure, we divided the total financial gain for all individuals accessing the co-located advice services (income gain and debt managed) using data from the Citizens Advice IT platform, by the cost of the service to funders over the 8 -month baseline data collection period. ${ }^{30}$

\section{Statistical analyses}

Analyses were carried out using Stata v.14. Descriptive analyses examined baseline advice recipient and propensity weighted comparator group characteristics. Propensity scores were calculated with logistic regression, with advice group membership as the dependent variable. ${ }^{31,32}$ Data were kernel weighted ${ }^{33}$ and comparator group members whose scores did not overlap with the distribution of advice group scores were excluded (online supplement DS1). Data were not imputed as missing covariate data were low $(5.27 \%)$ and loss to follow-up was not associated with the main outcomes.

The effect of co-located advice receipt was estimated by comparing the before-after change in advice receipt and comparator groups by including an interaction term between group and time (before-after indicator) in analytical models. To account for clustering within individuals and general practices, data were analysed using mixed-effects multilevel longitudinal regression models. ${ }^{34}$ All analyses specified robust standard errors, were weighted using the kernel weights and adjusted for indicators of missingness on propensity score covariates and loss to follow-up (educational attainment, household composition, household income and ethnicity).

Logistic regression models were used for binary outcomes (CMD caseness, financial strain), interaction coefficients were exponentiated and expressed as ratios of odds ratios (rOR). For count (consultation frequency) and continuous (well-being) outcomes we used Poisson and linear regression models respectively, interaction coefficients indicated the difference between the changes in outcome score by group. To examine the role of financial strain, associations between financial strain, advice receipt and the main outcomes were assessed. Adjustments were made for financial strain where a significant impact of advice on the main outcomes was found.

We re-ran analyses for the main outcomes, generating separate propensity scores for specific subgroups identified a priori on the basis of utility for commissioners (because of limited subgroup sample sizes to detect small effect sizes): gender (male/female); ethnicity (White, Black/Black British and other); long-term conditions status; and, whether or not individuals were recorded with, or self-reported, improvements since receiving advice in income, housing or employment.

\section{Results}

\section{Participants}

We recruited 278 of the 397 service users approached at baseline (70.0\%) (Fig. 1). Reasons for non-participation were 'refusal unknown reason' $(48,11.9 \%)$, 'trust' $(35,8.7 \%)$, 'no time' $(23$, $5.7 \%)$ and 'language' $(13,3.2 \%)$. Among the cohort of unique contacts recorded on the Citizens Advice IT platform over the baseline recruitment period, those recruited to the advice group were similar in terms of gender, age group, ethnic group and health status (online Table DS2). In total, 633 controls were recruited, of which 623 were included in analyses. We excluded controls whose propensity scores were outside the range of common support $(n=4)$ and who reported receiving welfare benefits/debt advice between baseline and follow-up $(n=6)$ (Fig. 1). We followed up 199 (71.6\%) individuals in the advice group and $530(85.1 \%)$ in the control group. Table 1 shows the
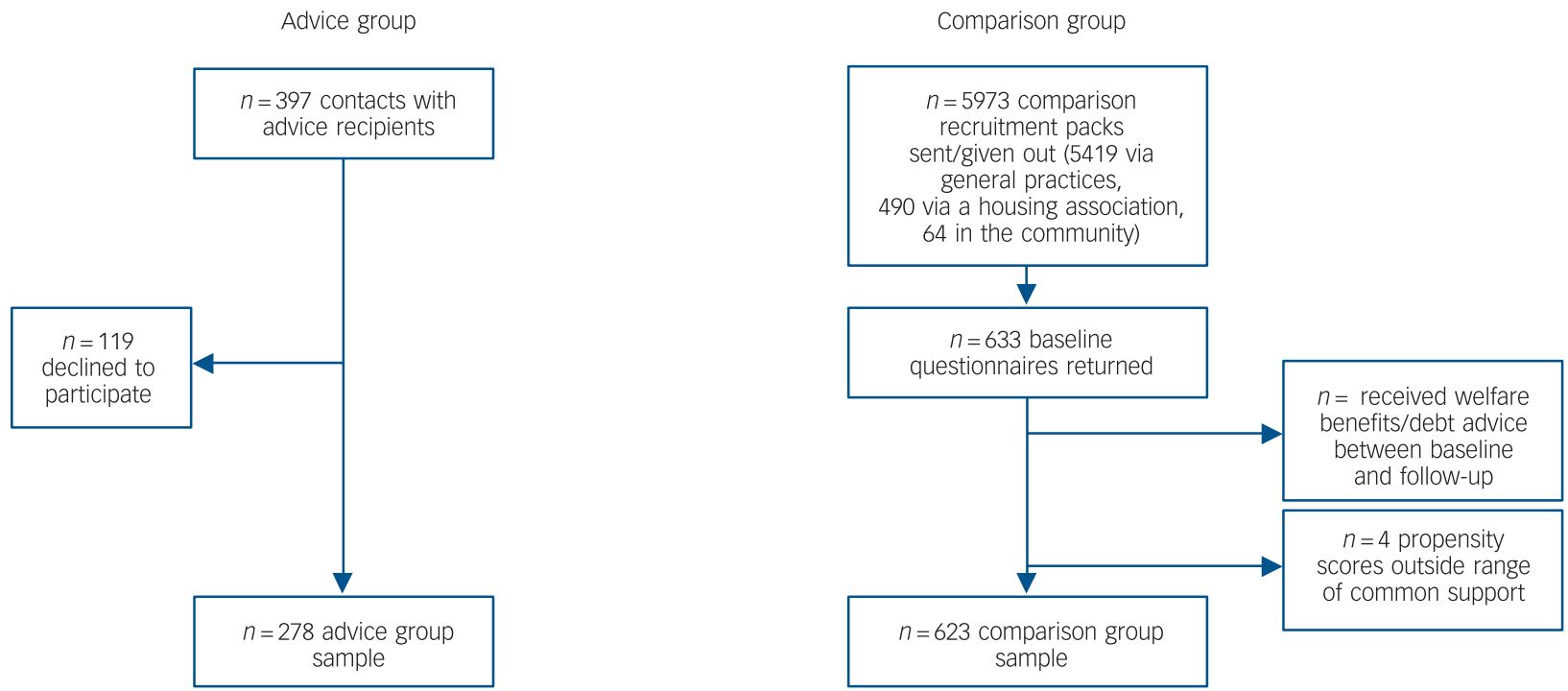

Fig. 1 Advice and comparison group sample flow chart. 
Table 1 Covariate distribution across propensity score weighted advice group and comparison group members

\begin{tabular}{|c|c|c|}
\hline & \multicolumn{2}{|c|}{$\%$} \\
\hline & $\begin{array}{l}\text { Advice } \\
(n=278)\end{array}$ & $\begin{array}{c}\text { Comparison } \\
(n=623)\end{array}$ \\
\hline \multicolumn{3}{|l|}{ Gender } \\
\hline Male & 36.7 & 39.5 \\
\hline Female & 63.3 & 60.5 \\
\hline \multicolumn{3}{|l|}{ Age group, years } \\
\hline $18-24$ & 1.5 & 1.6 \\
\hline $25-34$ & 9.3 & 11.7 \\
\hline $35-44$ & 22.2 & 16.9 \\
\hline $45-54$ & 26.8 & 32.7 \\
\hline $55-64$ & 28.4 & 25.0 \\
\hline $65-74$ & 6.3 & 8.5 \\
\hline $75+$ & 5.4 & 6.3 \\
\hline \multicolumn{3}{|l|}{ Ethnicity } \\
\hline White & 48.6 & 43.6 \\
\hline Black/Black British/mixed & 30.8 & 41.1 \\
\hline Asian/Asian British/mixed & 10.7 & 9.7 \\
\hline Other & 9.9 & 5.7 \\
\hline \multicolumn{3}{|l|}{ Marital status } \\
\hline Single & 42.9 & 41.9 \\
\hline Long-term relationship & 27.7 & 24.6 \\
\hline Ex-relationship & 29.5 & 33.5 \\
\hline \multicolumn{3}{|l|}{ Educational attainment } \\
\hline None & 41.3 & 33.5 \\
\hline Up to GCSE level & 24.1 & 30.7 \\
\hline Up to A level & 18.5 & 22.6 \\
\hline Degree and above & 16.1 & 13.3 \\
\hline \multicolumn{3}{|l|}{ Employment status } \\
\hline Unemployed & 18.9 & 22.2 \\
\hline Employed & 24.4 & 18.6 \\
\hline Retired & 14.0 & 13.3 \\
\hline Outside labour force & 42.7 & 46.0 \\
\hline \multicolumn{3}{|l|}{ Tenure } \\
\hline Owned/part owned & 10.2 & 9.3 \\
\hline Rented & 69.6 & 72.6 \\
\hline Rent free & 20.2 & 18.2 \\
\hline \multicolumn{3}{|l|}{ Household composition } \\
\hline Live alone & 43.6 & 40.3 \\
\hline Lone parent & 12.0 & 22.2 \\
\hline Live with partner with or without children & 27.8 & 21.0 \\
\hline Live with others/family & 16.6 & 16.5 \\
\hline \multicolumn{3}{|l|}{ Household income, $f$} \\
\hline $0-549$ & 57.9 & 53.6 \\
\hline $550-999$ & 24.3 & 30.2 \\
\hline$>1000$ & 17.8 & 16.1 \\
\hline \multicolumn{3}{|l|}{ Problems paying for housing } \\
\hline 0 & 34.7 & 41.9 \\
\hline $1+$ & 65.3 & 58.1 \\
\hline \multicolumn{3}{|l|}{ Health status } \\
\hline Disabled/long-term health condition & 72.6 & 74.6 \\
\hline Not disabled/no health condition & 27.5 & 25.4 \\
\hline
\end{tabular}

propensity score covariate distribution across the two groups following weighting.

\section{Estimating the impact of advice}

At follow-up, 64\% of the 199 people in the advice group reported at least one improvement since receiving advice. Of these the most common were: improved stress (25.9\% of responses), income (20.6\%), housing circumstances $(17.7 \%)$ and confidence (15.9\%) (online Fig. DS1).

\section{Mental health and well-being}

The proportion of individuals meeting criteria for CMD decreased over time to a greater extent among the advice group than the control group. However, the group $\times$ time interaction was not statistically significant (Table 2). Subgroup sample sizes and analyses are shown in Table 3 . The reduction in proportion meeting CMD criteria was significantly greater for the advice group relative to the controls among women ( $\mathrm{rOR}=0.37,95 \%$ CI $0.20-0.70, P=0.002$ ) and Black/Black British participants $(\mathrm{rOR}=0.09,95 \%$ CI $0.03-0.28, P<0.001)$.

We found no evidence for any difference in change in wellbeing scores between the two groups (Table 2). In subgroup analyses (Table 3 ), recipients who received a positive outcome from advice demonstrated significantly improved well-being scores compared with controls $(\beta=1.29,95 \%$ CI $0.25-2.32$, $P=0.015)$

\section{Consultation frequency}

The welfare advice group reported more frequent consultations than controls (12 month mean consultation frequency of 13.1 $($ s.d. $=12.8)$ compared with $8.6($ s.d. $=9.1))$. There was no evidence for an impact of advice on 3-month consultation frequency (Tables 2 and 3 ).

\section{Role of perceived financial strain}

Perceived financial strain was associated with CMD, well-being, consultation frequency and advice receipt (all $P<0.001)$. There was a significant improvement $(\mathrm{rOR}=0.42,95 \%$ CI $0.23-0.77$, $P=0.005)$ in financial strain among the advice group compared with controls (Table 2). Advice receipt was associated with significant reductions in financial strain among women (rOR $=0.33,95 \%$ CI $0.14-0.78, P=0.011)$, those with long-term conditions ( $\mathrm{rOR}=0.30,95 \% \mathrm{CI} 0.16-0.58, P<0.001)$ and those with positive advice outcomes $(\mathrm{rOR}=0.45,95 \%$ CI $0.28-0.74$, $P=0.001$ ) (Table 3).

For CMD, adjustments for financial strain reduced the strength of the interaction among women $(\mathrm{rOR}=0.48,95 \% \mathrm{CI}$ 0.24-0.97, $P=0.040$ ) but not among Black/Black British participants (rOR $=0.12,95 \%$ CI $0.04-0.38, P<0.001$ ). For wellbeing, adjustment for financial strain only partly accounted for

\begin{tabular}{|c|c|c|c|c|c|c|}
\hline & \multicolumn{2}{|c|}{ Baseline } & \multicolumn{2}{|c|}{ Follow-up } & \multirow{2}{*}{$\begin{array}{l}\text { Interaction group } \times \text { time, } \\
\text { rOR } / \beta \text { coefficient }(95 \% \mathrm{Cl})\end{array}$} & \multirow[b]{2}{*}{$P$} \\
\hline & Advice & Comparison & Advice & Comparison & & \\
\hline Participants with common mental disorder, ${ }^{a} \%$ & 79.5 & 68.6 & 62.6 & 56.5 & $0.57(0.30$ to 1.07$)$ & 0.078 \\
\hline Well-being, ${ }^{\text {b }}$ mean (s.d.) & $18.1(5.2)$ & $18.7(5.0)$ & $18.0(5.5)$ & $19.7(4.4)$ & $0.10(-0.74$ to 0.94$)$ & 0.814 \\
\hline Consultation frequency, ${ }^{\mathrm{c}}$ mean (s.d.) & $4.1(3.8)$ & $2.7(3.1)$ & $4.0(3.6)$ & $2.5(2.5)$ & $0.04(-0.20$ to 0.29$)$ & 0.730 \\
\hline Financial strain, ${ }^{\mathrm{d}} \%$ & 66.9 & 39.9 & 58.6 & 43.2 & $0.42(0.23$ to 0.77$)$ & 0.005 \\
\hline
\end{tabular}




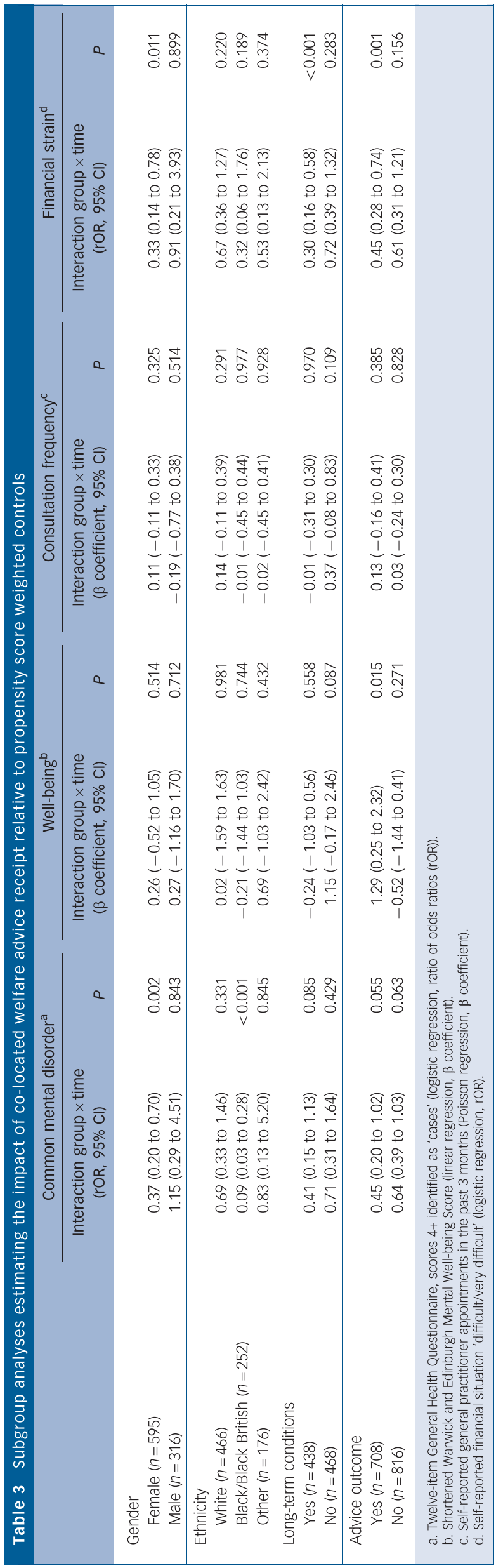

the impact of advice among those with a positive advice outcome $(\beta=1.12,95 \%$ CI $0.04-2.20, P=0.042)$.

\section{Financial support-seeking}

There was a significant impact of advice on reduced use of a credit card or overdraft if income did not cover participants' costs (rOR $=0.48,95 \%$ CI $0.26-0.90, P=0.021)$. Among supportseeking behaviours for financial-related problems, the advice group became more likely to report not knowing where to go to for support over time, compared with controls $(\mathrm{rOR}=2.33$, $95 \%$ CI 1.14-4.76, $P=0.021$ ). Similarly, there was a significantly greater increase in the proportion of advice recipients who did not know where they would seek help for the health impact of financial issues, relative to controls ( $\mathrm{rOR}=8.8,95 \%$ CI $1.56-$ 49.27), $P=0.014$ ). Controls became proportionately more likely to talk to their GP about the health impact of financial strains but there was no change over time among advice recipients, generating a significant group $\times$ time interaction $(\mathrm{rOR}=0.56$, 95\% CI $0.36-0.89, P=0.015$ ).

\section{Cost-consequences}

In total, $\mathfrak{E} 793135$ additional income (debt managed, income increases and one-off payments) was gained during the study period by recipients (average $\mathfrak{£ 2 6 8 9}$ per capita). The annual costs of the service to funders in $2015 / 16$ was $\mathfrak{E 7 9}, 000$, equating to

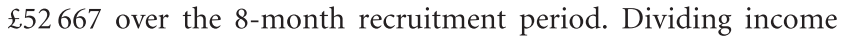
gain by cost over 8 months translates to $\mathfrak{k} 15$ income gain per $\mathfrak{k} 1$ funder contribution.

\section{Accessing the advice service}

Co-located advice recipients had most commonly heard about the service through their GP or practice staff, followed by Citizens Advice elsewhere, or other advice services (online Table DS1). Nearly all reported a preference to see a GP-located adviser. Open-ended responses indicated that this was because the service was easier to access (for example because of mobility problems or travel anxiety), nearer home or more convenient (129, 64.8\%); or, because it was a more familiar or less anxiety-provoking environment $(42,21.1 \%)$. If the service had not been available almost half of recipients would either not have sought advice at all, or would have spoken to their GP/other practice staff. Twofifths of recipients had already spoken to their GP about their advice issue. Of these, over half said this was because it was affecting their mental health or was otherwise health related.

\section{Discussion}

To our knowledge, this is the first controlled prospective summative evaluation of co-located welfare advice services in healthcare settings. The provision of co-located advice led to significant improvements in mental health and well-being. Specifically, CMD caseness reduced among women and Black/ Black British advice group recipients; and, those with a positive advice outcome also reported improvements in well-being. The strongest evidence was for a significantly greater reduction in perceived financial strain among the advice group compared with controls. This was reflected in an average financial gain of $£ 2689$ per capita among recipients. Compared with controls, advice recipients also reported enhanced coping strategies for dealing with financial strains; however, they were also more likely to report not knowing where to go to for support with financial 
strain or the health impact of such strains over time. No differences in self-reported consultation frequency were found.

\section{Explanations for the findings and comparison with literature}

Mental health and well-being

Our hypothesis that improvements in mental health and wellbeing linked to advice receipt would be mediated by reductions in perceived financial strain was partially borne out. Thus, financial strain was associated both with poor mental health and receipt of advice; and, where a significant impact of advice on mental health and well-being was found, this was partially accounted for by adjustments for financial strain. The hypothesis was not supported among Black individuals. This suggests there may be other underlying mechanisms between receipt of advice and improved symptoms of CMD in this group or that financial strain insufficiently captured any reductions in stress. A generalised measure of perceived stress may be a more useful gauge of the impact of advice and may also capture improvements linked to other non-directly financial outcomes (for example, housing circumstances). Improvements in mental health may also arise from other psychosocial factors such as perceived social support and/or from material changes in circumstances. ${ }^{18,35}$

Reduction in indebtedness may also underlie changes in mental health and well-being. We found a significant reduction in reported use of a credit card or overdraft if income did not cover costs among advice recipients, relative to the control group. This may be linked to debt management outcomes of advice and/or to budgeting information provided. This is important since use of credit cards and unauthorised overdrafts incur high interest rates, further increasing the likelihood of indebtedness, which is prospectively associated with poor mental health. ${ }^{3}$

\section{Consultation frequency}

It is possible that a reduction in appointments was not found because of the short follow-up period and/or recall bias, although validity of self-reported healthcare use has been reported as fair. ${ }^{36}$ Previous research using routinely collected medical record data found small reductions in GP consultation frequency and antidepressant prescription 6 months before and after receipt of co-located welfare advice. ${ }^{37}$ However, this research was small and uncontrolled, precluding causal inference.

\section{Financial support-seeking}

In contrast to the advice group, controls were more likely to talk to their GP about the impact on health or functioning of financial strain, and less likely to seek advice from the welfare agencies if unable to meet payments. Further, there was an increase among advice recipients of not knowing where to seek help. Since many recipients had been directed to the co-located service from high street Citizens Advice, these findings could be related to concurrent closures of such local services.

\section{Impact on GP non-health workload}

Our findings are in line with two recent UK GP surveys, ${ }^{38,39}$ in which GPs reported patient health, GP workload and practice staff time demands had been adversely affected by greater patient financial hardship and welfare provision changes. Our results suggest that reductions in financial strain could reduce practice burden and that co-location in health settings can target individuals less able to self-manage. This was evidenced by the proportion of advice recipients who would talk, or had already spoken, to their GP about their advice issue; by a preference to access advice at their general practice; and, by the proportion reporting that they would have gone to their GP, or would have not have sought advice, had the service not been there.

\section{Strengths and limitations}

A major strength of our research was the robust comparator group, allowing us to infer causality. Second, unlike previous research ${ }^{40}$ our study was sufficiently powered to detect significant differences over time. Third, we achieved similar or higher follow-up rates than have previously been reported. ${ }^{10}$ Fourth, we demonstrated that changes in perceived financial strain may be one, although not the only, underlying pathway linking advice to mental health. Fifth, by collecting data on health outcomes, service use and financial benefits accrued, we could provide data of direct value to commissioners.

This was a multisite study that increases the external validity of our results. However, all the sites examined were in London and served areas with high levels of multiple social disadvantage. Although these services are likely to be similar to other inner metropolitan areas, other urban and rural populations have differing sociodemographic population profiles and welfare needs. Nonetheless, co-located services provided in less urban UK locations also report that welfare benefits and debt are the main presenting issues and the income gain per capita is in line with other services. ${ }^{41}$ This supports the generalisability of our findings but further empirical testing is required.

Self-reported consultations data may be less accurate than those extracted from practice records. Capacity to extract such data was limited as appointments were not routinely recorded. Reduced accuracy (underreporting) has been linked to older age, longer time frame of recall, more frequent service utilisation and use linked to stigmatised issues. ${ }^{36}$ Although participants in both groups reported frequent GP consultations, the short recall time frame would have minimised inaccuracies. Further, as analyses compared change between the two groups (rather than absolute numbers), we have no reason to believe that the accuracy of self-report would have differed systematically over time. However, given the importance of this outcome to commissioners, future work should assess any change in service use over longer periods using objective measures.

As a quasi-experimental study, residual bias may arise if unmeasured variables exerted different influences on change over time in either group. However, we consider this risk to be small given the short follow-up and that the direction of change in the primary outcome was the same in both groups.

A potential disadvantage of the 3-month follow-up period is underreporting of the benefits of welfare advice. Data extracted from the Citizens Advice IT platform demonstrated that some individuals receive several episodes of advice over a longer period. We may therefore have collected outcome data for individuals in whom issues of concern are not fully resolved or for whom benefits may accumulate over time. Further, any impact of reduced financial strain on mental health and well-being may take longer to fully emerge and/or be muted among those chronically exposed to such stressors. ${ }^{42}$ Finally, our approach to assessing return on investment may underestimate the value of co-located welfare advice since analyses excluded non-monetised benefits, such as from mental health or housing improvements.

\section{Implications}

Co-located welfare advice can reach people who would not otherwise have sought advice or may otherwise turn to their GP 
for support. Advice recipients may experience improvements to short-term mental health, reduced financial strain and receive considerable financial returns. Although this study focuses on primary care, provision of advice services may benefit secondary mental healthcare service users at risk of underclaiming entitled welfare benefits, financial, housing and employment instability and poor financial capability. ${ }^{43,44}$ Pathways for the impact on reduced NHS and social care costs for this group have been hypothesised but not yet empirically tested. ${ }^{45}$ Further research on the impact of advice in different health settings and within new models of care that include aims to address wider determinants of health and health inequalities (such as multispeciality community providers and primary and acute care models), using objective measures of service use is needed.

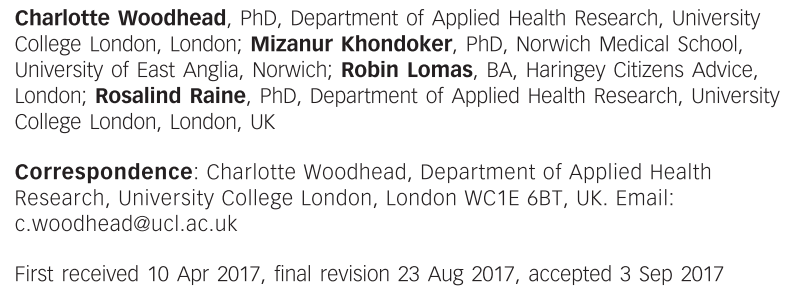

Charlotte Woodhead, PhD, Department of Applied Health Research, University College London, London; Mizanur Khondoker, PhD, Norwich Medical School, College London, London; Mizanur Khondoker, PhD, Norwich Medical Schoo,
University of East Anglia, Norwich; Robin Lomas, BA, Haringey Citizens Advice, University of East Anglia, Norwich; Robin Lomas, BA, Haringey Citizens Advice,
London; Rosalind Raine, PhD, Department of Applied Health Research, University College London, London, UK

Correspondence: Charlotte Woodhead, Department of Applied Health Research, University College London, London WC1E 6BT, UK. Email: c.woodhead@ucl.ac.uk

First received 10 Apr 2017, final revision 23 Aug 2017, accepted 3 Sep 2017

\section{Funding}

This research was funded by Haringey Council and the School for Public Health Research. The funders had no role in the study design, collection, analysis or interpretation of the data, in the writing of the article or in the decision to submit the article for publication. The study received National Institute for Health Research (NIHR) support through the Clinical Research Network. The views expressed are those of the authors and not necessarily those of the NHS, the NIHR or the Department of Health.

\section{Acknowledgements}

C.W. and R.R. were supported by the NIHR Collaboration for Leadership in Applied Health Research and Care (CLAHRC) North Thames at Bart's Health NHS Trust. The study received NIHR support through the Clinical Research Network. The views expressed are those of the Survey formatting, distribution and collation was supported by the Ipsos Mori Social Research Institute.

\section{References}

1 World Health Organization, Calouste Galbenkian Foundation. Social Determinants of Mental Health. World Health Organization, 2014.

2 Tunstall R, Bevan M, Bradshaw J, Croucher K, Duffy S, Hunter $\mathrm{C}$, et al. The Links Between Housing and Poverty: An Evidence Review. Joseph Rowntree Foundation, 2013.

3 Fitch $\mathrm{C}$, Hamilton S, Bassett $\mathrm{P}$, Davey R. The relationship between personal debt and mental health: a systematic review. Ment Health Rev J 2011; 16: 153-66.

4 Balmer NJ, Pleasence P, Buck A. Psychiatric morbidity and people's experience of and response to social problems involving rights. Health $\mathrm{SOC}$ Care Community 2010; 18: 588-97.

5 Balmer $\mathrm{NJ}$, Pleasence $\mathrm{P}$, Buck $\mathrm{A}$, Walker $\mathrm{H}$. Worried sick: the experience of debt problems and their relationship with health, illness and disability. Soc Policy Adm 2006; 5: 39-51.

6 Weich S, Lewis G. Poverty, unemployment, and common mental disorders: population based cohort study. BMJ 1998; 317: 115-9.

7 GPS at The Deep End Group. GPS at The Deep End: Improving Partnership Working between General Practices and Financial Advice Services in Glasgow: One Year on (Report 27). University of Glasgow, 2015.

8 Bloomer E, Allen J, Donkin A, Findlay G, Gamsu M. The Impact of the Economic Downturn and Policy Changes on Health Inequalities in London. UCL Institute of Health Equity, 2012.

9 Parkinson A, Buttrick J. The Role of Advice Services in Health Outcomes Evidence Review and Mapping Study. Consilium Research and Consultancy, 2015.
10 Adams J, White M, Moffatt S, Howel D, Mackintosh J. A systematic review of the health, social and financial impacts of welfare rights advice delivered in healthcare settings. BMC Public Health 2006; 6: 81

11 Woodhead C, Collins H, Lomas R, Raine R. Co-located welfare advice in general practice: a realist qualitative study. Health Soc Care Community 1 June 2017 (https://doi.org/10.1111/hsc.12453).

12 Howe LD, Tilling K, Galobardes B, Lawlor DA. Loss to follow-up in cohort studies: bias in estimates of socioeconomic inequalities. Epidemiol 2013; 24 $1-9$

13 Bonevski B, Randell $\mathrm{M}$, Paul C, Chapman K, Twyman L, Bryant J, et al. Reaching the hard-to-reach: a systematic review of strategies for improving health and medical research with socially disadvantaged groups. BMC Med Res Methodol 2014; 14: 42.

14 Rosenbaum PR, Rubin DB. The central role of the propensity score in observational studies for causal effects. Biometrika 1983; 70: 41-55.

15 Rosenbaum PR, Rubin DB. Reducing bias in observational studies using subclassification on the propensity score. J Am Stat AsSOC 1984; 79: 516-24.

16 Sianesi B. Implementing Propensity Score Matching Estimators with STATA UK STATA Users Group, VII Meeting, 2001 (http://fmwww.bc.edu/RePEc/ usug2001/psmatch.pdf).

17 Department for Communities and Local Government. English Indices of Multiple Deprivation 2015. Department for Communities and Local Government, 2015 (http://imd-by-postcode.opendatacommunities.org/).

18 Benzeval M, Bond L, Campbell M, Egan M, Lorenc T, Petticrew M, et al. How Does Money Influence Health? Joseph Rowntree Foundation, 2014

19 Pearlin LI, Schieman S, Fazio EM, Meersman SC. Stress, health and the lifecourse: some conceptual perspectives. I Health Soc Behav 2005; 46: 205-19.

20 Goldberg D, Williams P. General Health Questionnaire (GHQ). NferNelson 1988.

21 Stansfeld SA, Marmot MG. Social class and minor psychiatric disorder in British Civil Servants: a validated screening survey using the General Health Questionnaire. Psych Med 1992; 22: 739-49.

22 GL Assessment. General Health Questionnaire. GL Assessment (https:// www.gl-assessment.co.uk/products/general-health-questionnaire-ghq/) Accessed 21 Sep 2017

23 Tennant R, Hiller L, Fishwick R, Platt S, Joseph S, Weich S, et al. The Warwick-Edinburgh Mental Well-Being Scale (WEMWBS): development and UK validation. Health Qual Life Outcomes 2007; 5: 63.

24 Warwick Medical School. Warwick and Edinburgh Mental Wellbeing Scale: Guidance on Scoring. Warwick Medical School, 2015. (http:// www2.warwick.ac.uk/fac/med/research/platform/wemwbs/researchers/ guidance/).

25 Craig R, Mindell J. Health Survey for England 2012. The Health and Socia Care Information Centre, 2013

26 Institute for Social and Economic Research. Understanding Society the UK Household Longitudinal Survey. University of Essex, 2015 (https:// www.understandingsociety.ac.uk/).

27 Organisation for Economic Co-operation and Development International Network on Financial Education. Measuring Financial Literacy: Core Questionnaire in Measuring Financial Literacy: Questionnaire and Guidance Notes for Conducting an Internationally Comparable Survey of Financial Literacy. OECD, 2011.

28 University College London School of Laws. English and Welsh Civil and Social Justice Panel Survey: Waves 1-2, 2010-2012. University College London, 2015.

29 Taylor MF, Brice J, Buck N, Prentice-Lane E. British Household Panel Survey User Manual Volume A: Introduction, Technical Report and Appendices. University of Essex, 2010.

30 Kaufman R, Watkins R, Sims L, Crispo NS, Hall JC, Sprague DE. Costconsequences analysis: a case study. Perform Improv Q 1997; 10: 7-21.

31 Becker So, Ichino A. Estimation of average treatment effects based on propensity scores. Stata J 2002; 2: 358-77.

32 Brookhart MA, Schneeweiss S, Rothman KJ, Glynn RJ, Avorn J, Stürmer T. Variable selection for propensity score models. Am J Epidemiol 2006; 163 1149-56.

33 Leuven E, Sianesi B. PSMATCH2: Stata module to perform full Mahalanobis and propensity score matching, common support graphing, and covariate imbalance testing. Statistical Software Components, 2015.

34 Rabe-Hesketh S, Skrondal A, Pickles A. Generalized multilevel structural equation modelling. Psychometrika 2004; 69: 167-90.

35 Zimmerman FJ, Bell JF Income inequality and physical and mental health testing associations consistent with proposed causal pathway. J Epidemio Community Health 2006; 60: 513-21. 
36 Bhandari A, Wagner T. Self-reported utilization of health care services: improving measurement and accuracy. Med Care Res Rev 2006; 63: 217-35.

37 Krska J, Palmer S, Dalzell-Brown A, Nicholl P. Evaluation of welfare advice in primary care: effect on practice workload and prescribing for mental health. Prim Health Care Res Dev 2013; 14: 307-14.

38 lacobucci G. GPs' workload climbs as government austerity agenda bites. BMJ 2014; 349: g4300.

39 Citizens Advice. A Very General Practice: How Much Time do GPs Spend on Issues Other than Health? Citizens Advice, 2015.

40 Mackintosh J, White M, Howel D, Chadwick T, Moffatt S, Deverill M, et al. Randomised controlled trial of welfare rights advice accessed via primary health care: pilot study [ISRCTN61522618]. BMC Public Health 2006; 6: 162.
41 Derbyshire Citizens Advice Bureaux. Citizens Advice Bureaux in General Practice: Report 2011/12. Derbyshire Citizens Advice Bureaux, 2012.

42 Kahn JR, Pearlin LI. Financial strain over the life course and health among older adults. J Health Soc Behav 2006; 47: 17-31.

43 Slade $M$, Mccrone $P$, Thornicroft $G$. Uptake of welfare benefits by psychiatric patients. Psychiatrist 1995; 19: 411-13.

44 Holkar M, Mackenzie P. Money on Your Mind. Money and Mental Health Policy Institute, 2016 (http://www.moneyandmentalhealth.org/ moneyonyourmind/).

45 Parsonage M. Welfare Advice for People who use Mental Health Services: Developing the Business Case. Centre for Mental Health, 2013 (https:// www.centreformentalhealth.org.uk/welfare-advice-report).

\section{psychiatry in music}

\section{Punk rock made me a psycho-therapissed}

\section{David Meagher}

London, 1976. The filth and the fury as the nation's consciousness was gouged by an abrasive multisensory assault. Punk rock had arrived with all its naughtiness and disobedience! The essence of punk: be yourself, no matter how untidy or gauche, while urging DIY and self-empowerment ('here's three chords, now form a band').

Celebrating elements that were previously taboo, punk found in mental illness an ideal substrate that was presented in comic and/or glamourised terms. Perfectly, punk emerged just as deinstitutionalisation gained momentum, providing a youth-friendly optic of mental illness as societal exposure to individuals with mental illness increased. Key figures, such as Joey Ramone, spoke out about their personal experiences of mental ill health. A nation's youth dreamt of being 'so messed up' (possibly) from a 'teenage lobotomy'. The mainstream psychiatry of the 'psycho-mafia' (a title of a song by The Fall) was under attack!

Punk gave voice to a previously excluded community - reaching out to those stigmatised by prevailing values while rejecting self-stigma ('destroy what destroys you'). Negative stereotypes of mental illness were thrust back into society's face, reframed as desirable characteristics, all the while lampooning prejudice and discrimination.

For three frantic years punk rock pulverised the stale convention so that even when it delivered on its self-proclaimed destiny by crashing and burning, mainstream society was left with a changed perspective as the punk ethos endured beyond the music. For psychiatry, this has manifested in the rejection of complacency and a demand for continued change.

The Mad Pride movement of the 1990s drew substantially from the punk philosophy of do it yourself through direct action. Challenging negative attitudes by celebrating the positive aspects of madness ('we're out of the bin and glad to be mad') erstwhile terms of abuse were re-appropriated as symbols of positive identity. With one quarter of the stigma burden of mental illness attributed to the delivery of care by service providers, the psychiatric profession provided an attractive target ('psychiatrists, restrain yourselves').

And so into the 21st century where the philosophy of recovery has penetrated all things mental health, providing an antidote to the prognostic negativism of the medical model for severe mental illness, offering hope and empowerment. The core tenets of recovery share considerable commonality with the ethos of punk rock - self-direction, respect and responsibility, person-centred, strengths-based, empowerment readily translating to the punk notions of DIY, positive action, self-efficacy, inclusiveness, and challenging misinformed convention via anti-hierarchical beliefs.

Psychiatry will always be the punk rock of medicine. For those who enjoyed their formative years as psychiatrists to the tune of punk, the movement seared our brains with an indelible scar, providing permission to think outside of the box, to challenge convention and to believe that everybody can make a useful contribution. Thus, as funding for mental health continues to diminish across high-income countries, despite increasing youth suicide and the stark reality that the life expectancy of those with enduring mental illness is 17 years less than the general population, more than ever we must challenge the source of these inequalities. Anything less would be, to paraphrase that Rotten genius, 'an inexpensive vacation in the suffering of others'. Never 